\title{
The generic medicines system in Italy: scenarios for sustainable growth
}

\author{
Federico Fontolan ', MA; Silvia Zucconi', MStat; Carlo Piccinni', PhD
}

\begin{abstract}
In this paper, an overview is provided of the present Italian generic medicines system. Data on generic medicines market share and enterprise performance were reviewed and discussed, and the results of a survey completed by general practitioners (Computer Assisted Web Interview), pharmacists (Computer Assisted Web Interview) and patients (Computer Assisted Personal Interview) are presented. How potential policies on manufacturing and exports affect the industry in Italy are also explored. The results show that generic medicines in Italy have a lower market share than in other major European countries. This is mainly because general practitioners are uncomfortable with generic medicines companies, in particular those whose chain of production is unclear to them. A series of obstacles to diffusion of generic medicines also persists at a legislative level, such as payback and patent linkage. Manufacturing and exports in Italy could benefit from the manufacture of generic medicines before patent expiry, which would enable exports to countries with different expiry dates.
\end{abstract}

Keywords: Economic sustainability, generic medicines, manufacturing provision, pharmacoeconomics

\section{Introduction}

The current phase of economic stagnation in Italy reflects a structural slowdown that began over 20 years ago. Some industrial sectors, however, have shown an increasing capacity to promote economic and occupational growth. This study was conducted at the Nomisma Economic Research Institute (www. nomisma.it), and a complete overview is presented here of the generic medicines system in Italy. Specifically, the focus is on how the generic medicines system functions in Italy and on elements that could contribute to further developing the sector.

We attempted to define the real potential of the generic medicines industry and how it can be reached, while weighing up the unavoidable need to rationalize public spending. We searched for potential developments and how the effect of generic medicines can be optimized within the complex market dynamics, regulations and practices of the pharmaceutical industry. inherently contributes to the process of public expenditure rationalization.

According to Nomisma's estimates on the prices of the top 20 generic medicines sold in Italy, based on IMS data, and in line with another analysis [1], it can be projected that the average price of a generic medicine can reduce by $60 \%$ per unit within a year of entering the market. This is in contrast to savings of up to 95\% achieved in other European countries [2-4]. During the past four years, this dynamic has allowed an increase in sales and a concomitant reduction in the total amount spent on medicines by the National Health Service in Italy, see Figure 1. In particular, in August 2012, the Italian Government attempted to increase prescribing of generic medicines by introducing a reform requiring Italian general practitioners to prescribe generic medicines. This resulted in some controversy over interchangeability and possible switching between equivalents [5]. Despite this and other
We conducted a multi-level analysis. First, we established the present 'status quo' of regulations, market trends, behaviours and experiences of patients, and the role and influence exerted by general practitioners and pharmacists. Assumptions were then made and near-future scenarios simulated to estimate the potential for industrial development of generic medicines companies in the coming years and to define policy actions that could foster this growth.

\section{The current situation}

The generic medicines sector is particularly suitable for linking costcontainment needs with the potential for industrial growth. As such, it

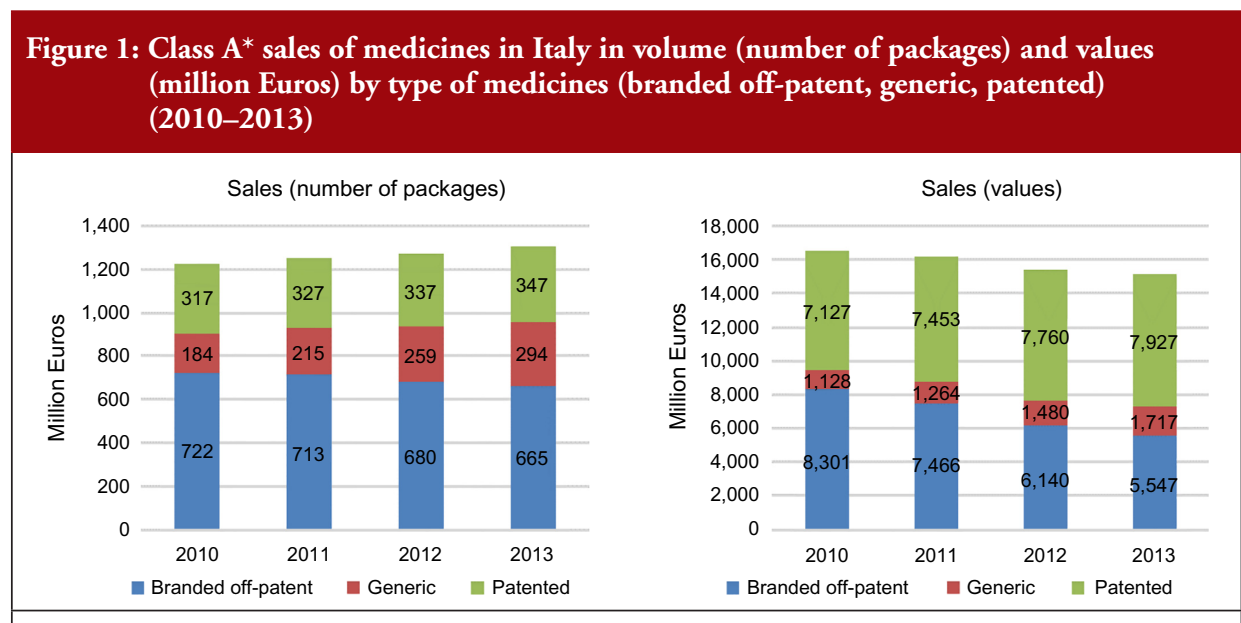

*Class A refers to medicines that are sold outside the hospitals and reimbursed by the National Health Service.

Source: Nomisma calculations based on IMS Health data processed by the Assogenerici Study Centre

Author for correspondence: Federico Fontolan, MA, Project Manager, Nomisma Economic Research Institute, 44 Strada Maggiore, IT-40125 Bologna, Italy

Submitted: 24 May 2016; Revised: 9 August 2016; Accepted: 12 August 2016; Published online first: 25 August 2016 


\section{Figure 2: Indices of amortization and value added $(2005=100)$ from balance sheet data for} generics companies and non-generic pharmaceutical producers in Italy (2005-2013)

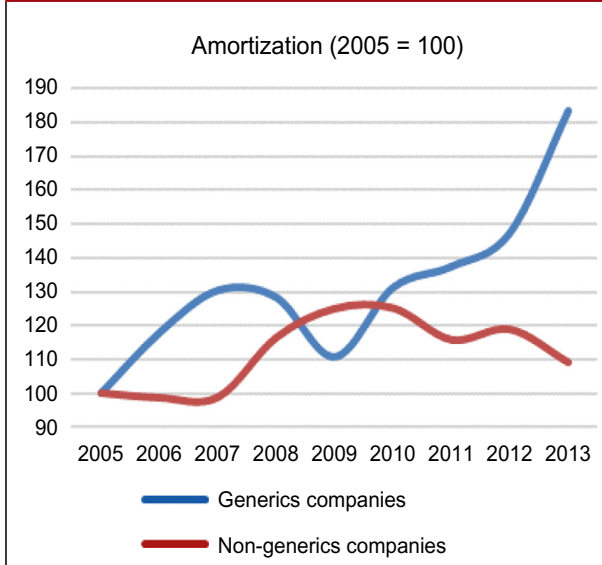

Source: Nomisma calculations based on data from AIDA-Bureau [18]

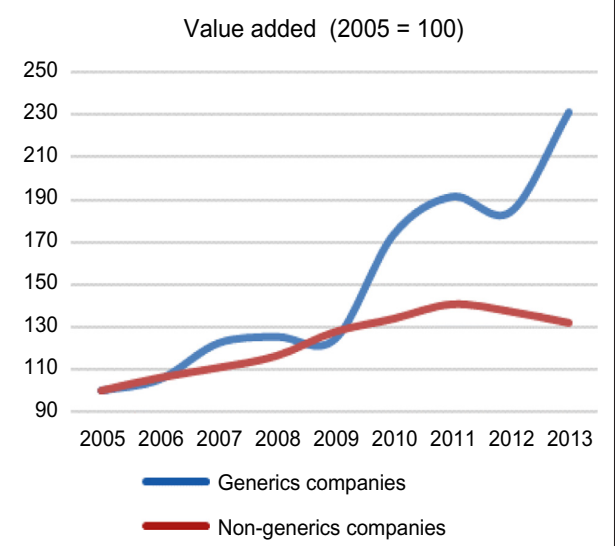

Despite the clear advantages of generic medicines for the economy and public and private spending, it

\section{Box 1: Methodological details on survey process}

The survey implemented in this study aimed to:

- investigate real behaviours, not opinions or perceptions

- use the survey results as a complementary database for the impact analysis.

Participants included physicians and pharmacists, whose anonymity was guaranteed. This was viewed as essential for acquiring precise and accurate information. Sensitive information, e.g. name and surname of the participant, was not requested. Some simple, yet optional demographic information, useful for data analysis, was requested.

The information was collected using the Computer Assisted Web Interview (CAWI) method, an online questionnaire. The questionnaire could be accessed via a web page dedicated exclusively to the survey in which the respondents could input their answers.

The Federation of Associations of Italian Pharmacists (Federazione Ordini Farmacisti Italiani) helped recruit pharmacists by promoting the survey on its website as well as through its own provincial professional orders, which encouraged their members to take part in the survey.

A mailing list was used to recruit physicians. The physicians' contact details (mail or telephone number) were made available by the Local Health Authorities (LHAs) or by specialized companies.

The representativeness of the survey results was guaranteed by means of creating a large and complete physician database.

Physicians mainly participated in the survey by completing an online questionnaire. A telephone survey was implemented with the only aim of ensuring an effective coverage of the sample basis in all regions.

The patient surveys were conducted within pharmacies via CAPI (Computer Assisted Personal Interview) in four sample cities selected on the basis of their geographical location and population size.

Use of CAPI allowed respondents to directly interact with an interviewer and gave them the opportunity to be shown pictures of the main sorts of generic drugs in the initial phase of the interview. This method ensured the correct identification of the product category under investigation; as a consequence, it also guaranteed minimization of possible approximation errors of the responses. The optimal sample size of each survey was chosen to limit the sampling error of the estimates and of the single fields of study. As a result, each survey involved a number of sample units ensuring the representativeness of the target universe of each of them. Below the number of responses to each survey:

1. Patient survey: out of a sample of 797 patients, 569 of them take generic drugs; this number of interviews provides a sampling error of $4.1 \%$ with a confidence interval of $95 \%$.

2. Physician survey: the sample is made up by 651 units providing a sampling error of 3.8\% at a confidence level of $95 \%$.

3. Pharmacist survey: 449 owners of pharmacies were interviewed; the sample size ensures maximal margin of error of $4.6 \%$ for the overall estimates on the entire target population. 
is evident that the generic medicines market has not yet reached its full potential. At present, generic medicines account for just over $13 \%$ of spending on Class A medicines.

The growth of the generic medicines industry is mainly influenced by the behaviours of physicians, pharmacists and patients. As such, this study implemented three different surveys designed to explore the experiences of general practitioners, pharmacists and patients, relating to generic medicines. In particular, the surveys aimed to investigate the reasons for certain behaviours (the methodological details on the survey process are reported in Box 1).

Overall, an unbalanced picture has emerged. On the one hand, results show that $90 \%$ of patients know about generic medicines, $72 \%$ having used them in the past 12 months. On the other hand, many general practitioners continue to prescribe the well-known branded products and not the equivalent mainly for two reasons: the market availability of several generics for the same active substance, which could cause confusion among patients who have to take a given drug; and insufficient information on the reliability of generic medicines companies, see Figure 3, which could be a result of an 'information gap' between general practitioners and generics manufacturers.

The persisting unstable economic situation, and a consequent decrease of purchasing power for a consistent part of the population, might lead to an increase in the levels of consumption of generic drugs in substitution for more expensive branded drugs. Patient confidence in generic medicines is increasing, and this is reflected in the opinions of the patients themselves, pharmacists and general practitioners. In addition, patients are increasingly turning to alternative sources of information for treatment advice, indicating that future generations will be less reliant on general practitioners. To facilitate this transition, generic manufacturers and distributors will have to take steps to bridge this information gap and establish an exchange of information with general practitioners based on reciprocal transparency, see Figure 4. Moreover, it is essential to increase patient awareness of the safety and efficacy of generic drugs by emphasizing that use of these products does not compromise their care, as shown in several studies [7-12].

\section{Future perspectives}

The study primarily focuses on predicting how generic medicines may fare in the future in terms of public and private savings, as well as the development of the sector in an industrial context. Over the next few years (2015-2020), the process of genericization, i.e. the process in which a brand-name drug becomes a generic drug after the expiration of its patent, has the potential to increase the market share from its present $13 \%$, worth Euros 1.7 billion (value based on Class A retail prices). Assuming that price dynamics remain in line with recent trends, the cumulative effect of genericization on public spending was estimated. This indicated that genericization could allow for savings of public funds in excess of Euros 1.3 billion between

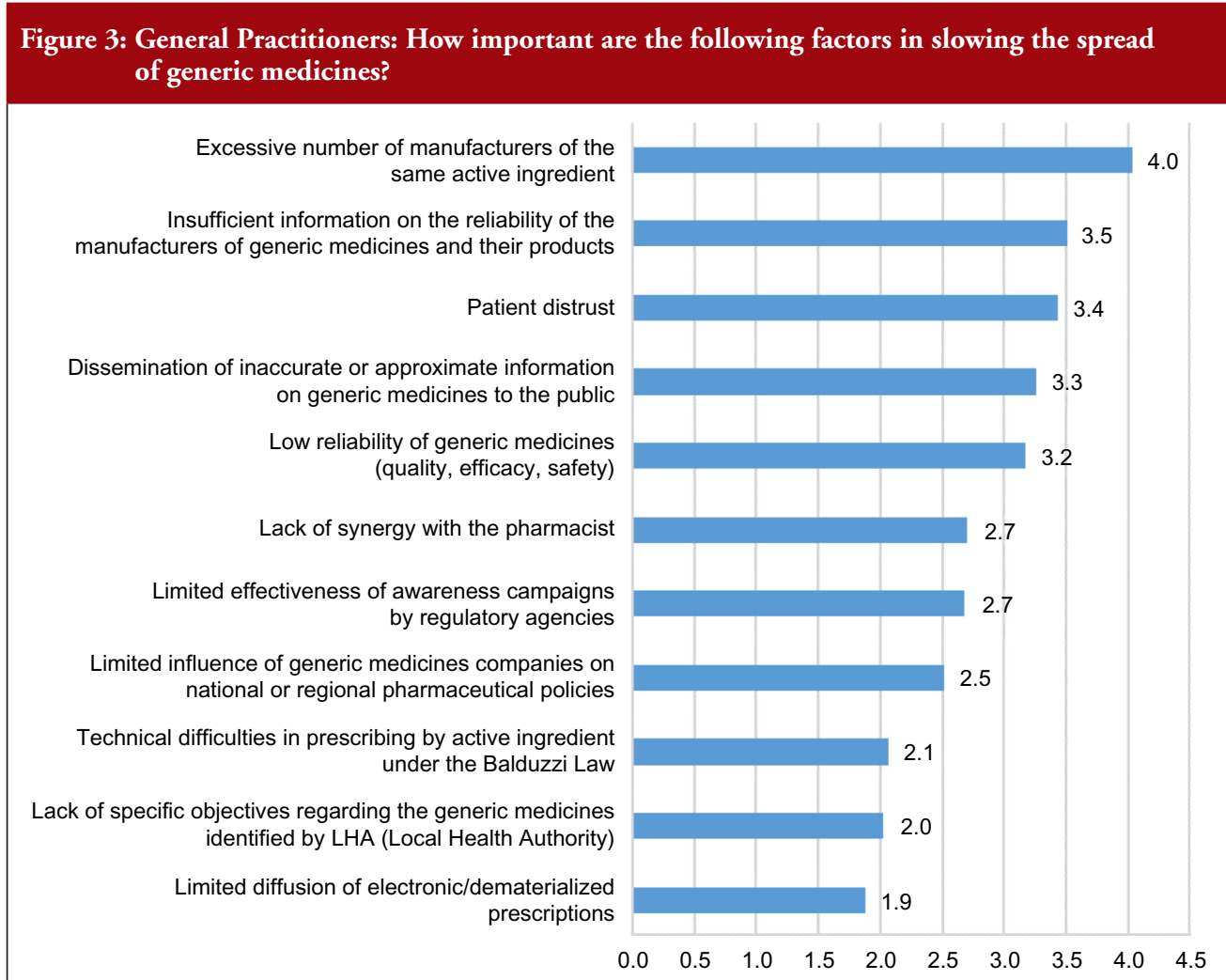

(Average grade: $1=$ no importance; $5=$ utmost importance)

Source: Nomisma survey of general practitioners
2015 and 2020. As savings to the National Health Service depend on price fluctuations, and not on the market shares of generic medicines, all the calculated savings will directly benefit the National Health Service, regardless of the higher or lower market shares of generics themselves, see Figure 5.

In addition, savings from individual expenditure can also be made. As outlined above, the amount spent on generic medicines only makes up a small percentage of pharmaceutical spending as a whole. In addition, generic medicines still only account for a minority share of the off-patent market, with originator medicines retaining a $70 \%$ share of total off-patent sales.

Therefore, a second simulation sought to determine how much people would actually save by replacing the originator medicine with the equivalent generic medicine at the lowest price available. The National Health Service in Italy currently only 


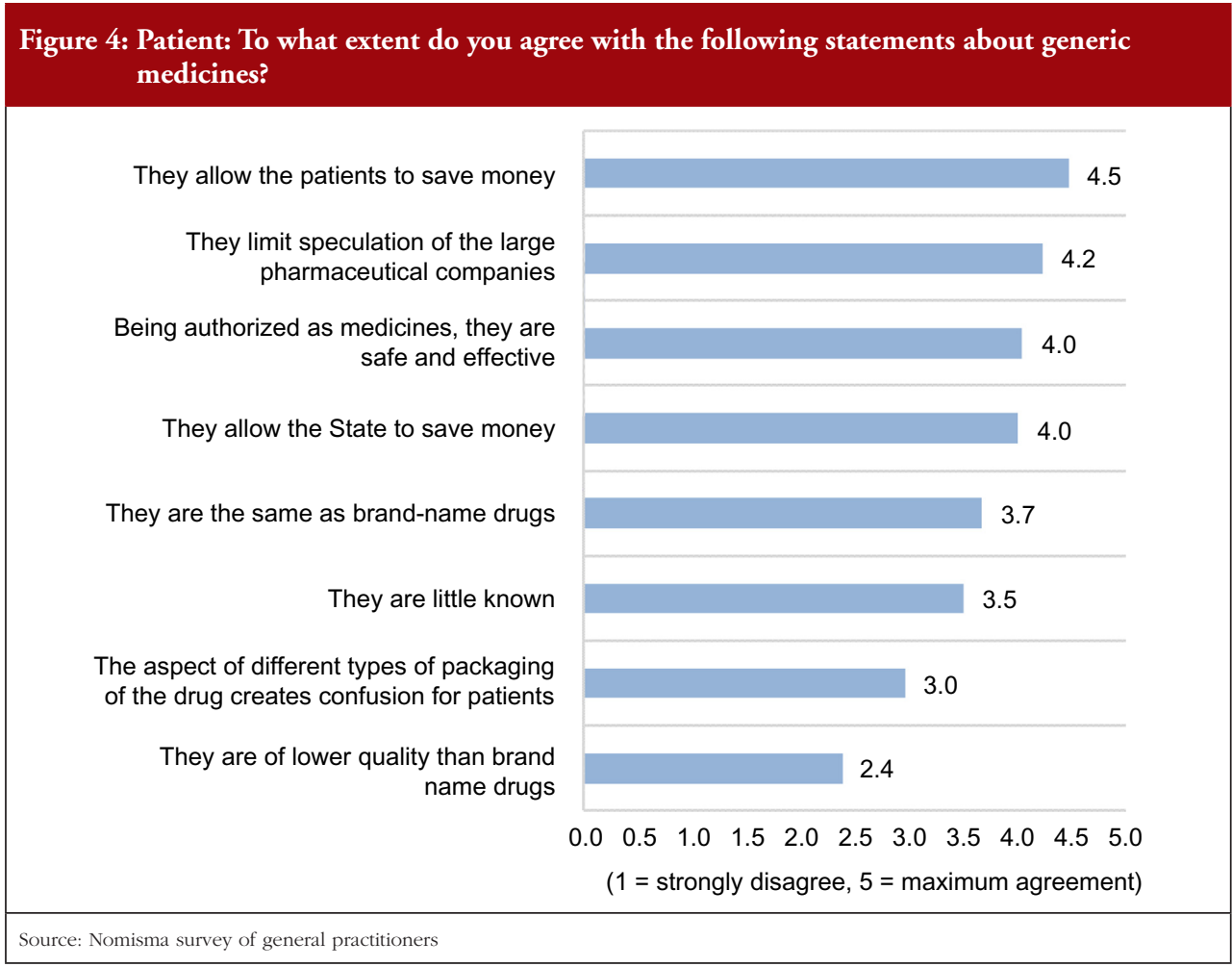

led to increased Class A generic medicines, few Class $C$ generic medicines are available. As such, there is an even greater potential for private savings to be made should more Class $\mathrm{C}$ generic medicines enter the market.

The high potential for private savings is shown in Table 1: if patients were to replace all medicines used with their respective lower cost generic medicine, private savings of over Euros 1.4 billion could be made. The latter element also assumes the form of private savings, thus representing a substantial increase in income, given that it can be achieved without reducing consumption. Here, the private savings achieved could fuel an increase in consumption in several sectors of the economy. By using the average propensity for consumption calculated by the Bank of Italy, the increase in the overall consumption generated by the private saving coming from generics can be estimated to be around Euros 700 million.

\section{Figure 5: Estimate of maximum savings obtainable by the National Health Service in 2015-2020 due to the patent expiry process - cumulative savings}

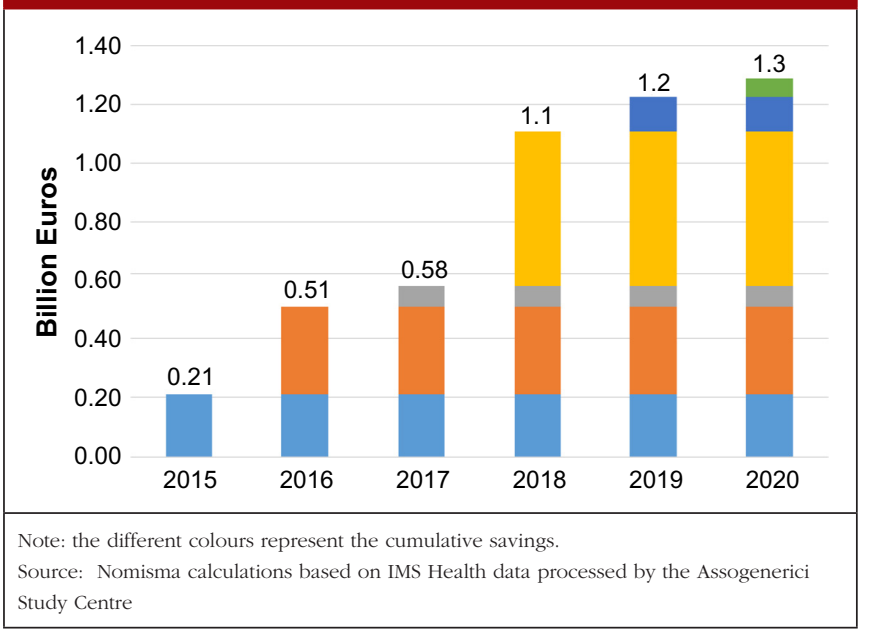

reimburses Class A medicines at the lowest price available (reference price), the remaining share is paid by patients if they opt to purchase a more expensive version of the drug. In 2013, this additional cost paid by individuals reached approximately Euros 900 million. Our simulation calculated the amount of private savings obtainable if the share of generic medicines were to gradually increase to the point where only generic medicines are sold. This simulation included not only the Class A market, but also the Class $C$ (medicines that are not reimbursed by the National Health Service). While pressure to reduce public spending has
To shift the analysis from a focus only on savings to one that looks at prospects of industrial growth in Italy, the study also addressed the effects of patents that are due to expire before 2020. A model derived from a recent paper by Vicente and Simoes [13] was used for this estimate. Starting from the value of pharmaceutical spending at retail prices over a given period of time, the model estimated the effect of associated manufacturing revenue and related employment. By applying this method to the Italian system, it was possible to estimate how much manufacturing revenue could be generated by generic medicines manufacturers operating in Italy after the forthcoming expiration of patents period (2015-2020).

Patents of various Class A and Class C pharmaceutical products, worth more than Euros 2.1 billion, are due to expire between 2015 and 2020. How much this potential market can contribute to national industrial production, in terms of growth, was estimated in three different scenarios. The baseline scenario (Scenario 1) gauged the expected output under current conditions; the two subsequent scenarios were developed based on certain assumptions of policy and market changes. First, assumptions relating to policy interventions that could modify the expected outcomes were introduced (Scenario 2); second, some assumptions about market trends were applied (Scenario 3). The policy interventions taken into consideration, see Box 2, would allow generic medicines companies operating in Italy to produce and export medicines before patent expiration to allow domestic companies to be more competitive compared with those outside Europe operating under a less stringent patent protection system. 


\begin{tabular}{l} 
Table 1: Potential private annual savings and increased private consumption in other sectors \\
triggered by increasing the generics market share (10\%, 30\%, 50\%, 100\%) \\
\begin{tabular}{|l|l|l|l|l|l|}
\hline \multirow{2}{*}{ Private savings } & Euros & $\mathbf{1 0} \%$ & $\mathbf{3 0} \%$ & $\mathbf{5 0} \%$ & $\mathbf{1 0 0} \%$ \\
\hline & Maximum & $276,322,779$ & $442,936,193$ & $793,348,728$ & $1,463,707,828$ \\
\cline { 2 - 7 } & Minimum & $226,082,274$ & $362,402,340$ & $649,103,505$ & $1,197,579,132$ \\
\hline Additional consumption & Maximum & $132,634,934$ & $212,609,373$ & $380,807,389$ & $702,579,757$ \\
\cline { 2 - 6 } & Minimum & $108,519,492$ & $173,953,123$ & $311,569,682$ & $574,837,983$ \\
\hline Source: Nomisma calculations based on data from Jappelli and Pistaferri $[17]$
\end{tabular} \\
\hline
\end{tabular}

\section{Scenario analysis}

The first scenario assumed that the market penetration capacity and the trend in generic medicine prices will reflect the historic trend recorded over the past five years, and that the share of generic medicines produced in Italy will remain constant (50\% according to data from the recent Assogenerici (Italian Association of Generic and Biosimilar Medicines Industry) internal survey and observations from generics companies). This suggested that, during the period 20152020, the cumulative manufacturing turnover that could be produced by generic medicine companies in Italy is about Euros 87 million.

The second scenario assumed that the market penetration capacity and trend in the prices of generic medicines remain constant, as in the first scenario, but, as a result of manufacturing provision, the percentage of generic medicines produced in Italy increases. In other words, the scenario simulates the case of a hypothetical law provision that would allow generics companies in Italy to produce the medicines before the patent expiration date. Such a provision would improve the time to market of enterprises; therefore, it would become more convenient to produce in Italy rather than import the medicines from a country outside the EU. In this case, the additional manufacturing turnover that would be produced by generics companies operating in Italy could exceed Euros 175 million during the same time period.

Finally, the third scenario assumed that by removing some obstacles specific to the Italian market, the market share and price of generic medicines can align with the European average, and manufacturing provisions will increase the share of generic medicines produced in Italy. In this scenario, the additional manufacturing turnover that could be produced by generic medicines companies operating in Italy is more than Euros 319 million during this time period, see Figure 6.

It is important to highlight that the proposed scenarios 2 and 3 estimated the maximum obtainable effect. In other words, the scenarios estimated the maximum manufacturing turnover that could be activated if the entire national demand were to be satisfied by Italian production and if all generic medicines were to achieve certain market shares. It is clear that these are not the most likely scenarios, but they do enable the upper limit to be defined.

It is also important to reiterate why it is appropriate to include the 'additional' manufacturing turnover in scenarios 2 and 3 .

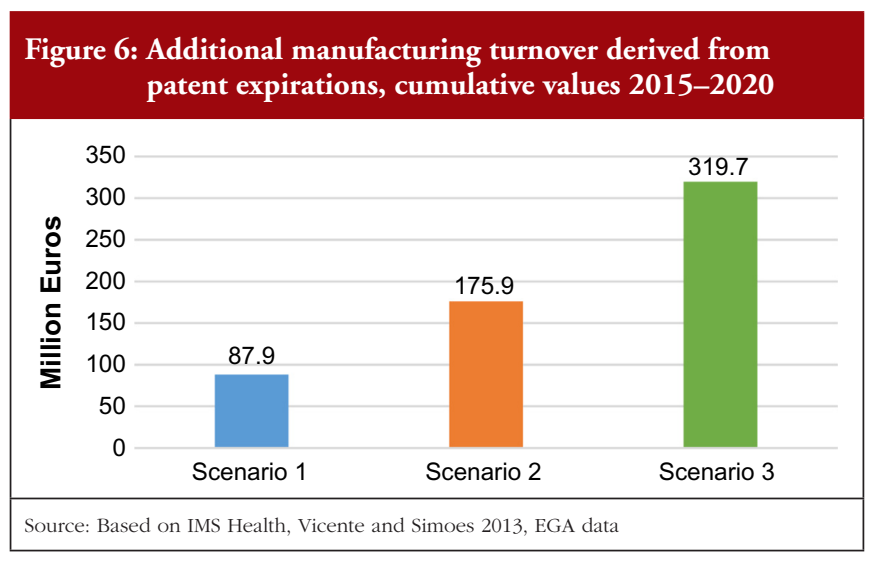

Box 2: Manufacturing and export provisions

What are manufacturing and export provisions? At present, patent protection regulations do not allow European generic medicines companies to start producing pharmaceuticals before expiration of the patent. This situation is the indirect cause of a now widespread phenomenon of 'regulatory dumping', through which companies operating in countries with a less stringent patent protection system enjoy a competitive advantage. This is the primary reason for the vast phenomenon of shifting development and production of medicines outside national and European borders. This mechanism also limits the effect of upcoming patent expirations on the European industrial system.

To enhance the possible positive effect of genericization in terms of industrial development, it is possible to simulate the implementation of specific policy mechanisms, which may affect the reindustrialization of the sector. In particular, our analysis considered the effects derived from manufacturing and export provisions. The manufacturing provision is a mechanism that allows companies operating in Italy to begin production of generic medicines even before patent expiration. This is designed to improve their 'time to market' and to improve the competitiveness of their products compared with those of other international producers not subject to the same patent constraints. The export provision is a mechanism that permits production before patent expiration and also allows the export of products to countries where patents have already expired, even though they are still in force in Italy.

These mechanisms would allow companies operating in Italy to be competitive and to make the next period of patent expiration an opportunity for industrial recovery and substantial drug price reduction. The possible effect of such rules was simulated to determine the maximum effect obtainable from forthcoming patent expirations. 
A natural consequence of the upcoming patent expirations will be a decline in medicine production by originator companies, regardless of whether or not generic medicine companies are able to start producing the medicines before patent expiration. The envisioned policy interventions could influence the geographical location of generic medicines production, favouring manufacture in Italy and Europe.

Finally, it should be stressed that the estimates are conservative, as they do not take into account any increase in quantities sold. The process of genericization in recent years has been accompanied by both a constant reduction in price and an increase in quantities sold. This effect is linked to the growth in the demand for medicines, related to the natural process of population ageing, and also, as a direct result of genericization, some medicines become more accessible to lower income patients. It is therefore likely that the estimates calculated in the three scenarios underestimated the real effect on manufacturing.

The scenario simulations had taken into account the possible activation of manufacturing confined to internal demand. In other words, estimates focused on how much additional manufacturing turnover the generic medicines companies could produce, considering the current size of the market is Euros 2.1 billion. An estimate of how much turnover could be produced by companies operating in Italy to satisfy foreign demand could also be added.

Specific data on the sales of Italian generic medicines in international markets were not available. As such, we used another estimation technique. On the basis of available numbers from companies balance sheets and an informal survey that we conducted on Italian generics producers, we estimated that generic medicines companies operating in Italy generate $52 \%$ of their sales domestically and $48 \%$ in foreign markets. It was assumed that this ratio of sales will remain as such over the coming years, i.e. for every Euro of sales generated in the domestic market, Italian generic medicines companies will have nearly another Euro of sales abroad. To make the estimate more conservative, this ratio was slightly decreased and the ratio between domestic and foreign revenues set to equal 60/40. Starting from these baseline assumptions, the potential manufacturing turnover generated by foreign demand was estimated as a percentage additional to that already calculated for the domestic market. Taking this into account, the resulting scenarios suggested that additional manufacturing turnover could be even more significant, see Table 2.

Additional manufacturing output is naturally associated with increased employment that can be estimated in terms of its direct components (using the average productivity per employee in

\begin{tabular}{|c|c|c|c|c|c|}
\hline \multicolumn{6}{|c|}{$\begin{array}{l}\text { Table 2: Summary of the potential effects of combining the manufacturing and } \\
\text { export provisions in the three scenarios }\end{array}$} \\
\hline Scenario & $\begin{array}{l}\text { Additional } \\
\text { manufacturing } \\
\text { revenues (Euros) }\end{array}$ & $\begin{array}{l}\text { Additional units } \\
\text { produced (tablets, } \\
\text { vials ...) }\end{array}$ & $\begin{array}{l}\text { Additional } \\
\text { direct jobs }\end{array}$ & \begin{tabular}{|l} 
Additional \\
indirect \\
jobs
\end{tabular} & $\begin{array}{l}\text { Total } \\
\text { additional } \\
\text { jobs }\end{array}$ \\
\hline Scenario 1 & $149,507,346$ & $4,983,578,197$ & 1,246 & 3,115 & 4,361 \\
\hline Scenario 2 & $299,014,692$ & $9,967,156,394$ & 2,492 & 6,229 & 8,721 \\
\hline Scenario 3 & $543,473,206$ & $18,115,773,517$ & 4,529 & 11,322 & 15,851 \\
\hline
\end{tabular}

the pharmaceutical industry in terms of units produced per year, as a reference) and indirect components (using an employment multiplier derived from the literature [13]). Overall, the additional jobs that could be created in the upcoming years following the genericization process will vary greatly, depending on the legislative and regulatory context. These will range from a minimum of 4,361 jobs activated under scenario 1 , to over 15,800 jobs in the case where certain policies for the promotion of industrial growth of the sector are pursued (scenarios 2 and 3).

\section{From potential to possible policy actions}

To capture the full potential of industrial development and the public and private savings described so far, at least three types of intervention are suggested: 'passive' interventions to remove the main obstacles to growth in the process of rationalizing public expenditure; 'active' interventions aimed at facilitating the implementation of scenarios with the greatest positive impact; and change of perspective: moving from a perspective that focuses on savings, to one that takes into account the overall effects of policy choices, in particular those related to the development of manufacturing processes.

\section{'Passive' interventions}

This category includes interventions that could remove obstacles for generic medicines companies. This would enable them to consolidate their production base, be active in a competitive market and not need to rely on the support of public subsidies. In this regard, three particular elements were analysed: the existence and possible effects of the payback mechanism for public overspending; the risk of the remaining patent linkage mechanisms in the Italian system in terms of lost savings; and the expected consequences of a hypothetical system of tenders in the national retail pharmaceutical system.

The payback mechanism is imposed to safeguard pharmaceutical spending by assigning an annual budget to individual pharmaceutical companies (generic and originator). In the event that this budget is exceeded, the companies themselves have to pay for spending above the ceiling imposed. Although the mechanism is effective in limiting overspending, it does not allow generic medicines companies to acquire a significant market share, thus being a decisive factor in slowing the expansion of generic medicines. A simple simulation for 2013 clearly demonstrated this. In 2013, the amount of payback to be refunded by pharmaceutical companies should have been Euros 29,175,355; because of the activation of the fund for innovative medicines, no payments were requested from companies in 2013. It can, however, be expected that this type of compensation will not always be available as a result of the natural growth of the market share of generic medicines companies, of which about one-third (27.92\%, equal to Euros $7,995,128$ ) was payable by generic medicines companies despite the fact that they only represent $13 \%$ of the overall market. A simple simulation calculated the payback with the insertion of a correction based on the market share of companies. This simulation yielded a cumulative estimate, taking into account the total payback that would have, in theory, been borne by generic medicines companies and estimating the 


\begin{tabular}{|c|c|c|c|}
\hline & $\begin{array}{l}\text { Profits before } \\
\text { taxes (Euros) }\end{array}$ & $\begin{array}{l}\text { Payback } \\
\text { (Euros) }\end{array}$ & $\begin{array}{l}\% \text { payback on } \\
\text { profits before } \\
\text { taxes }\end{array}$ \\
\hline \multicolumn{4}{|l|}{ Current system } \\
\hline Generics companies* & $91,996,008$ & $7,995,128$ & 8.7 \\
\hline $\begin{array}{l}\text { Other pharmaceutical } \\
\text { companies** }\end{array}$ & $1,579,572,233$ & $13,886,388$ & 0.9 \\
\hline \multicolumn{4}{|c|}{ System with payment linked to market shares } \\
\hline Generics companies* & $91,996,008$ & $2,406,967$ & 2.6 \\
\hline $\begin{array}{l}\text { Other pharmaceutical } \\
\text { companies** }\end{array}$ & $1,579,572,233$ & $19,474,549$ & 1.2 \\
\hline \multicolumn{4}{|c|}{$\begin{array}{l}\text { "This includes companies eligible for the payback in } 2013 \text {, representing } 65 \% \text { of all generics } \\
\text { companies in terms of revenues. } \\
\text { "In order to make a weighted comparison with non-generics companies, a subgroup } \\
\text { of non-generics companies was created comprising } 65 \% \text { of the companies in terms of } \\
\text { revenues. } \\
\text { Note: Both scenarios simulate the case in which the innovative companies in the national } \\
\text { pharmaceutical industry did not breach the budget and hence covered the entire payback. } \\
\text { Source: Based on data from Assogenerici and AIDA-Bureau van Dijk [18] }\end{array}$} \\
\hline
\end{tabular}

adjustment of their market share in terms of the overall value of Class A generic pharmaceutical spending. This estimate can be reconfigured by taking company budgets by a single active ingredient into account. A cumulative estimate provides an overall picture of the direction and dimension of the mechanism.

Table 3 shows how the burden of payback would change (compared with profit before taxes) if this method based on market value share distribution was used. In the current case, the 2013 payback borne by generic medicines companies would have been Euros 7,995,128 if the budget breach had not been covered by the fund for innovative medicines (taking into consideration companies affected by the burden of payback, which accounts for $65 \%$ of the generic medicines companies in terms of revenue). This payback would have been equivalent to an $8.7 \%$ reduction in generic medicines company profits. For other pharmaceutical companies, the payback would have meant a decrease in before-tax operating income of only $0.9 \%$, effectively creating an imbalance between the two groups of companies. In contrast, the application of this mechanism according to market value shares would reduce this imbalance: in this hypothetical case, the total burden of the payback would amount to $2.6 \%$ of profit before taxes for generic medicines companies, and $1.2 \%$ for the remaining pharmaceutical companies.

There is also an aspect of patent linkage present in Italian law that creates an additional obstacle for generic medicines. This legal provision prevents generic medicines with a patent or Supplementary Protection Certificate (SPC) close to expiry, from qualifying as reimbursable by the National Health Service. This is not dependent on any pending litigation that could lead to the invalidity of the patent or SPC. As the risk of litigation increases when a molecule is close to patent expiry, the risk of delayed market entry also increases. Moreover, pharmaceutical companies adopt 'evergreening', a legal and business strategy that enables technology producers with expiring product patents to retain the royalties from them, by either taking out new patents (for example, over associated delivery systems, or new pharmaceutical mixtures), or by buying out or frustrating competitors for longer periods of time than would normally be permissible under the law. These tactics are designed to prolong the 'patent life' of products by as much as possible [14]. Different strategies are available to contrast this phenomenon and to encourage the prescription of generics, especially for those therapeutic widely used, such as Proton Pump Inhibitors or statins. These strategies, that can be collated under the ' 4 Es' - education, engineering, economics and enforcement - have been shown to be efficient in different European countries, such as Sweden and the UK [15], and they can be reinforced also in Italy. Moreover, an effective tactic should include monitoring media and communications in relation to possible disinformation attempts, especially if originated by pharmaceutical companies, as was the case with Sanofi being fined by French authorities [16].

The initial potential effect of patent linkage on the Italian market can be estimated through a hypothesis that considers the values of the patents that are due to expire in the next five years. Taking into account the average price reduction resulting from entry of generic medicines ( $-60 \%$ for Class A medicines), the potential effects of patent linkage can be estimated in terms of foregone savings. Such foregone savings have been conservatively calculated, assuming a six-month delay in the marketing of generic medicines. Historical prices dynamic shows that, in Italy, the average price slightly decreases $(-4 \%$ on average) in the year before the patent expires. Figure 7 simulates the situation in which patent linkage slows the marketing of medicines by changing the percentage of expected price reduction and thus bringing it closer to $-4 \%$ rather than to $-60 \%$. Overall, the worst-case scenario could lead to more than Euros 700 million in foregone savings between 2015 and 2020, see Figure 7.

Finally, with the hypothesis of a system of tenders in the retail national pharmaceutical system, two crucial elements have emerged from the study. First, a comparative analysis with other countries, namely Germany, clearly revealed the risks associated with this type of system. It is appropriate to acknowledge, however, that the tender system has worked adequately in some areas such as The Netherlands and Sweden.

Second, the direct surveys of Italian general practitioners and pharmacists collected the views that these individuals have on the possible introduction of a tendering system.

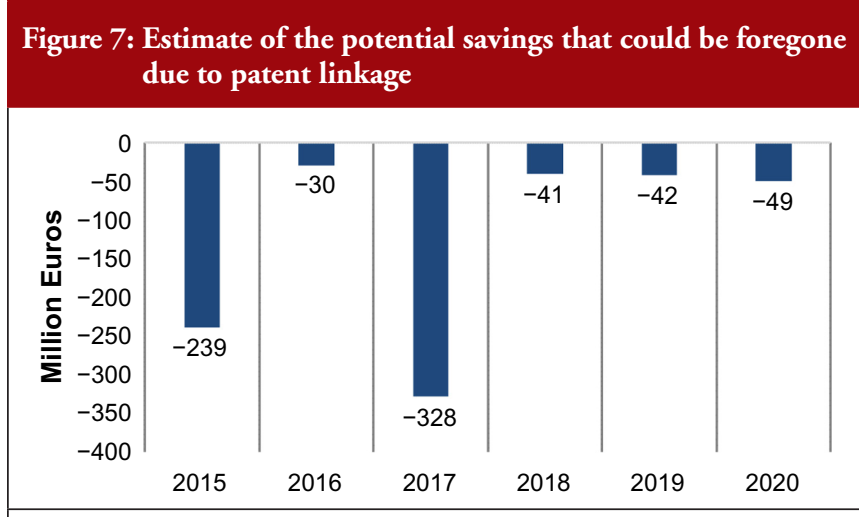

Source: Nomisma calculations based on data from IMS Health processed by the Assogenerici Study Centre 
The main problems associated with a tendering system are reduced capacity of generic medicines companies to enter into the market; risk of excessive pressure on the supply chain leading to a risk of shortages; excessive pressure on prices and uncertainty in planning, possibly putting many small and medium-sized enterprises out of business; increase in administrative costs; and risk of creating oligopolies.

From the surveys, $57.3 \%$ of general practitioners and $40.3 \%$ of pharmacists (data not shown) did not agree with a tendering system in the retail pharmaceutical system, highlighting how this could result in a risk of patient confusion, restrictions to general practitioner prescribing, and clinical risks in sudden changes in drug kinetics.

\section{Conclusions}

In this study, we aimed to analyse the latest developments in the generic medicines system in Italy, in light of the limitations resulting from the reduced public spending and the potential for growth and expansion of generic medicines.

The data and estimates calculated suggest that, before looking at public expenditure, in the coming years the development of the sector could be assessed and planned from an industrial policy perspective. Giving preference to this view does not imply that cost-containment processes are not relevant. On the contrary, data showed that, with a more sustained level of growth, stabilization and strengthening of the generic medicines industry in Italy, higher saving margins could be achieved. The mechanisms to attain this goal include: economy of scale effects, and efforts to strengthen the national production structure so as to increase the market share of generic medicines and improved quality perception by general practitioners and patients. In this sense, the study embraced an industrial perspective for formulating new policy options, i.e. an approach that addresses the major effects of industrial development of the sector at various levels, see Figure 8.

A targeted industrial policy could promote the comeback of industrial pharmaceutical production in Europe and Italy, through

\section{Figure 8: Policy proposals to change the system of generic drugs}

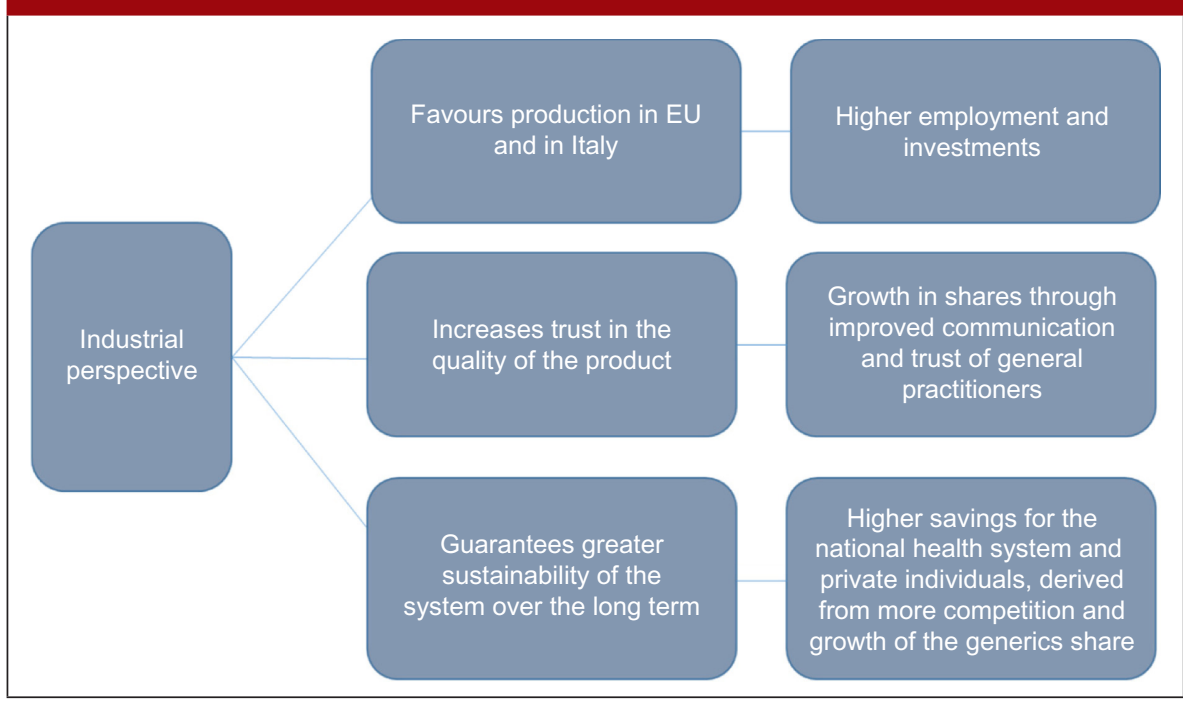

the use of ad hoc measures to allow manufacturing of patented products for export to countries with different patent regulations. This type of regulation would not only serve to create more jobs and investments, particularly in view of the upcoming patent expirations, but also to increase the perceived quality level of generic medicines, thus promoting greater acceptance with consequent effects on public and private savings.

In addition, using an industrial policy perspective means that the level of competition between companies can be influenced and stimulated. In the case of generic medicines, some of the mechanisms implemented to contain public health spending in recent years have created bottlenecks that make it difficult for companies to be competitive and increase investments over the medium term. A clear case of this is the payback mechanism, which makes it more difficult for generic medicines companies to increase its market share and, therefore, to contribute to the increase in overall savings. Decision-makers must choose whether to aim for an increasingly competitive framework or an overgrown legislative structure that discourages investments and competition.

Beyond resorting to specific alternative mechanisms, which we have sought to address by estimating their positive and negative effects, the key to ensuring the sustainability of the system is to consider growth in the generic medicines production sector as an industrial priority. As such, the generic medicines sector would be able to guarantee more employment and investment and ensure the stability of the system, as it is able to generate public and private savings under conditions of safety and traceability. The current regulatory context, however, actually impedes this process of expansion and paradoxically makes it more difficult to achieve additional potential savings, creating an obstruction in the very place where there could be room for growth and savings.

This concept is directly related to a change in perspective: the promotion of industrial growth in the generic medicines sector would result in greater savings over the medium term, ensured by more competition between companies and an increase in the positive perception of generic medicines. The current system could also distort the perception of generic medicines through the 'regulatory dumping' phenomena (which led to an increase in generic medicines imported from non-EU countries), whereas a new approach might improve this perception through a production system that is more Italian-based and transparent.

In conclusion, we pinpoint three key elements to promote such a system: a clear and definitive commitment of companies to increase production in Italy; a system with equal opportunities for all pharmaceutical companies, with the removal of the obstacles to growth; and an initiative extending to the European level to promote the reindustrialization processes that could be accomplished in the next five years. 


\section{Acknowledgements}

The authors thank Elisabetta Poluzzi (University of Bologna), Nello Martini (AccMed - Italian National Academy of Medicine), Luca Dondi Dall'Orologio, Sergio De Nardis, Filip Stefanovic, Evita Gandini, Pasquale Valente, Chiara Volpato (Nomisma Economic Research Institute) for their expert advice in the interpretation and discussion of the study results.

\section{Prior posting}

The main findings of this study were presented in an ad boc meeting on 5 May 2015 at the Parliament of the Italian Republic, Rome, Italy. The complete study can be downloaded from the Assogenerici website: http://www.assogenerici.org/2011/nomisma_doc/form-nomisma2015.html

\section{Funding sources}

The study was funded by Assogenerici, the Italian Association of Generic and Biosimilar Medicines Industry.

\section{Authors' comments}

Complete summary of results coming from the questionnaires can be found in the abstract* presented as oral communication during the 37 th National Congress of the Italian Society of Pharmacology, Napoli, 27-30 October 2015.

The abstract* was published in the electronic abstract book of the congress and it is available via: http://congresso.sifweb.org/ abs/682.pdf

*Poluzzi E, Piccinni C, Fontolan F, et al. Experience with generic medicines in Italy: a questionnaire-based survey of prescribers, pharmacists and patients [Abstract at the 37th National Congress of the Italian Society of Pharmacology (Napoli, 27th-30th October 2015)]. Available from: http://congresso.sifweb.org/abs/682.pdf

Disclosure of financial and competing interests: Federico Fontolan (FF), Silvia Zucconi (SZ) and Carlo Piccinni (CP) have received a financial grant from Assogenerici - Italian Association of Generic and Biosimilar Medicines Industry - to conduct this study. FF, SZ and CP declare that they have full control of all primary data and that they agree to allow the journal to review their data if requested.

Provenance and peer review: Not commissioned; externally peer reviewed.

\section{Authors}

Federico Fontolan ${ }^{1}$, MA

Silvia Zucconi ${ }^{1}$, MStat

Carlo Piccinni ${ }^{2}$, PhD

${ }^{1}$ Nomisma Economic Research Institute, 44 Strada Maggiore, IT-40125 Bologna, Italy

${ }^{2}$ Department of Medical and Surgical Sciences, Pharmacology Unit, University of Bologna, 48 Via Irnerio, IT-40126 Bologna, Italy

\section{References}

1. Magazzini L, Pammolli F, Tortolini V. Dinamiche di mercato e intensità della concorrenza di prezzo nel segmento dei farmaci off patent. La posizione
dell'Italia nel contesto europeo. March 2014. CERM. Availabe from: http:// www.cermlab.it/dinamiche-di-mercato-e-intensita-della-concorrenza-diprezzo-nel-segmento-dei-farmaci-patent-la-posizione-dellitalia-nel-contestoeuropeo/

2. Woerkom Mv, Piepenbrink H, Godman B, et al. Ongoing measures to enhance the efficiency of prescribing of proton pump inhibitors and statins in The Netherlands: influence and future implications. J Comp Eff Res. 2012;1(6):527-38.

3. Godman B, Wettermark B, Hoffmann M, et al. Multifaceted national and regional drug reforms and initiatives in ambulatory care in Sweden: global relevance. Expert Rev Pharmacoecon Outcomes Res. 2009;9(1):65-83.

4. Godman B, Bishop I, Finlayson AE, Campbell S, Kwon HY, Bennie M. Reforms and initiatives in Scotland in recent years to encourage the prescribing of generic drugs, their influence and implications for other countries. Expert Rev Pharmacoecon Outcomes Res. 2013;13(4):469-82.

5. Poluzzi E, Veronese G, Piccinni C, et al. Switching among equivalents in chronic cardiovascular therapies: 'real world' data from Italy. Basic Clin Pharmacol Toxicol. 2016;118(1):63-9.

6. Italian Medicines Agency. National Report on Medicines use in Italy. Year 2014 (English edition) [homepage on the Internet]. [cited 2016 Aug 9]. Available from: http://www.agenziafarmaco.gov.it/it/content/national-reportmedicines-use-italy-year-2014-english-edition

7. Dylst P, Vulto A, Godman B, Simoens S. Generic medicines: solutions for a sustainable drug market? Appl Health Econ Health Policy. 2013;11(5): 437-43.

8. Gagne JJ, Choudhry NK, Kesselheim AS, et al. Comparative effectiveness o generic and brand-name statins on patient outcomes: a cohort study. Ann Intern Med. 2014;161(6):400-7.

9. Kesselheim AS, Stedman MR, Bubrick EJ, et al. Seizure outcomes following the use of generic versus brand-name antiepileptic drugs: a systematic review and meta-analysis. Drugs. 2010;70(5):605-21.

10. Kesselheim AS, Misono AS, Lee JL, et al. Clinical equivalence of generic and brand-name drugs used in cardiovascular disease: a systematic review and meta-analysis. JAMA. 2008;300(21):2514-26.

11. Paton C. Generic clozapine: outcomes after switching formulations. Br J Psychiatry. 2006;189:184-5.

12. Veronin M. Should we have concerns with generic versus brand antimicrobial drugs? A review of issues. JPHSR. 2011;2(3):135-50.

13. Vicente V, Simoes S. Manufacturing and export provisions: impact on the competitiveness of European pharmaceutical manufacturers and on the creation of jobs in Europe. J Generic Med. 2014;11(1-2):35-47.

14. Vernaz N, Haller G, Girardin F, et al. Patented drug extension strategies on healthcare spending: a cost-evaluation analysis. PLoS Med. 2013;10(6): e1001460.

15. Godman B, Shrank W, Andersen M, et al. Comparing policies to enhance prescribing efficiency in Europe through increasing generic utilization: changes seen and global implications. Expert Rev Pharmacoecon Outcomes Res. 2010;10(6):707-22.

16. Baumgärtel C; Godman B; Malmstrom RE, et al. What lessons can be learned from the launch of generic clopidogrel? Generics and Biosimilars Initiative Journal (GaBI Journal). 2012;1(2):58-68. doi:10.5639/gabij.2012.0102.016

17. Jappelli T, Pistaferri L. Fiscal policy and MPC heterogeneity. CFS Working Paper, No. 2013/14. ECONSTOR. [cited 2016 Aug 9]. Available from: https:// www.econstor.eu/handle/10419/87681

18. Bureau van Dijk. Company information and business intelligence. Aida database. [cited 2016 Aug 9]. Available from: http://www.bvdinfo.com/en-gb/ our-products/company-information/national-products/aida

DOI: 10.5639/gabij.2016.0503.029

Copyright (C) 2016 Pro Pharma Communications International 